\title{
Intercorrências Clínicas em Hemodiálise Ambulatorial: Intervenções do Enfermeiro
}

\author{
Clinical Intercurrences in Outpatient Hemodialysis: Nurse Interventions
}

\author{
Vânia Aparecida dos Santos ; Harroldo Ferreira ${ }^{\mathrm{b}}$; Marcio Luiz dos Santos*b \\ a'Universidade Brasil, Programa de Pós-Graduação Stricto Sensu em Docência em Saúde SP, Brasil. \\ bUniversidade Anhanguera Unian, Programa de Pós-Graduação Stricto Sensu em Biotecnologia e Inovação e Saúde, SP, Brasil. \\ *E-mail: marcio.l.santos@educadores.net.br
}

\begin{abstract}
Resumo
Os rins têm função vital, pois são responsáveis pela eliminação de toxinas, regulação do volume de líquidos e pela filtragem do sangue (filtram, por minuto, em média $20 \%$ do volume sanguíneo bombeado pelo coração). Dessa forma, a função renal é avaliada com base na filtração glomerular (FG) e sua redução é observada na doença renal crônica (DRC), quando ocorre a perda das funções reguladora, excretora e endócrina dos rins. Desequilíbrios esses que podem ser de consequência vascular, por comorbidade secundária, por doença renal secundária a drogas ou agentes tóxicos, infecções urinárias de repetição, doença de próstata, doenças policísticas renal, entre outras. Nas terapias renais substitutivas, a diálise é empregada para remover líquidos e produtos residuais urêmicos do organismo, quando o corpo não consegue mais fazê-lo. Tendo em vista que o procedimento hemodialítico tem complicações potenciais, considera-se vital que o enfermeiro deva estar apto para intervir em tais intercorrências, portanto, ficando evidente a importância deste estudo. Objetiva-se, portanto, descrever as intervenções do enfermeiro em intercorrências clínicas durante a hemodiálise ambulatorial, bem como descrever as principais intercorrências durante as sessões de hemodiálise ambulatorial e se há protocolos específicos de intervenções do enfermeiro em intercorrências com o paciente dialítico. Trata-se de uma pesquisa de revisão integrativa da literatura, pois esta metodologia de revisão tem por propósito realizar uma dada síntese rigorosa de todas as pesquisas encontradas relacionadas a uma questão específica.
\end{abstract}

Palavras-chave: Enfermagem. Hemodiálise. Intercorrências.

\begin{abstract}
The kidneys have a vital function, as they are responsible for eliminating toxins, regulating the volume of fluids and filtering the blood (they filter, on average, $20 \%$ of the blood volume pumped by the heart per minute). Thus, renal function is assessed based on glomerular filtration $(F G)$ and its reduction is seen in chronic kidney disease (CKD), when the loss of the kidneys regulatory, excretory and endocrine functions occurs. These imbalances can be of vascular consequence, secondary comorbidity, kidney disease secondary to drugs or toxic agents, recurrent urinary infections, prostate disease, polycystic kidney diseases, among others. In renal replacement therapies, dialysis is used to remove uremic fluids and waste products from the body when the body is unable to do so. Bearing in mind that the hemodialysis procedure has potential complications, it is considered nodal that the nurse must be able to intervene in such complications, therefore, the importance of this study is evident. Therefore, the objective is to describe the nurse's interventions in clinical complications during the outpatient hemodialysis, as well as to describe the main complications during the outpatient hemodialysis sessions and if there are specific protocols for the nurse interventions in complications with dialysis patients. It is an integrative literature review research, since this review methodology aims to perform a given rigorous synthesis of all the studies found related to a specific issue.
\end{abstract}

Keywords: Nursing. Hemodialysis. Complications.

\section{Introdução}

A insuficiência renal é uma síndrome clínica que tem como característica principal a incapacidade dos rins de executarem suas funções, por conseguinte, essas toxinas se acumulam, provocando manifestações cardíacas e neurológicas graves (GUEDES et al., 2016).

Para Guedes et al. (2016), o sistema urinário exerce várias funções essenciais para homeostase corporal. Suas funções envolvem: a formação da urina, a excreção de produtos residuais, o equilíbrio hidroeletrolítico, a regulação da pressão arterial e função endócrina. Uma disfunção no sistema renal promove várias complicações no sistema orgânico humano. Dependendo do tipo de comprometimento, o indivíduo pode ser identificado com um quadro renal crônico.
De acordo com Santos et al. (2013), os rins têm função vital, pois são responsáveis pela eliminação de toxinas, regulação do volume de líquidos e pela filtragem do sangue (filtram, por minuto, em média $20 \%$ do volume sanguíneo bombeado pelo coração). Dessa forma, a função renal é avaliada com base na filtração glomerular (FG) e sua redução é observada na doença renal crônica (DRC), quando ocorre a perda das funções reguladora, excretora e endócrina dos rins. Quando a FG atinge valores inferiores a $15 \mathrm{~L} / \mathrm{min} / 1,73 \mathrm{~m} 2$, indica a falência funcional renal (FFR), comprometendo os demais órgãos.

$\mathrm{Na}$ fase inicial da FFR, as medidas terapêuticas básicas adotadas são, o controle da hipertensão arterial e a ingestão restrita de proteínas. Com o avanço da doença renal, o tratamento é medicamentoso, variando de acordo com as complicações e com as comorbidades apresentadas pelo 
paciente (SANTOS et al., 2013).

Esta pesquisa visa realizar estudos sobre a atuação do enfermeiro diante do paciente submetido à hemodiálise, considerando que contribuirá para profissionais envolvidos ao tratamento destes pacientes, bem como avaliar o conhecimento dos profissionais de enfermagem sobre o assunto, pois se compreende que a formação profissional na graduação pode não ser suficiente em função de tal especificidade da terapêutica, logo, requerendo especialização.

Concomitantemente e tendo em vista que o procedimento hemodialítico tem complicações potenciais, considera-se fundamental que o enfermeiro deva estar apto para intervir em intercorrências durante as sessões de hemodiálise .

O interesse por essa temática está imbricado em experiência profissional vivenciada pela pesquisadora, no ano de 2014, como técnico em enfermagem em uma clínica de hemodiálise no município de Santo André, na região do ABC Paulista. Experiência que trouxe inquietações intensificadas à medida que os anos subsequentes foram chegando e na dinâmica de seu processo de formação profissional no curso de graduação em enfermagem na FAMA - Faculdade de Mauá.

Identificou-se a importância de mais estudos voltados para as intervenções do enfermeiro em intercorrências durante a sessão de hemodiálise, uma vez que a atuação da equipe de enfermagem, durante todo o atendimento ao paciente submetido a este tratamento, é extremamente complexa e repleta de particularidades.

Um enfermeiro com especialização e experiência nesta área terá, sem dúvidas, embasamento para treinar e supervisionar sua equipe, buscando assim, excelência na prestação do cuidado, minimizando riscos à saúde dos pacientes.

Este estudo tem como objetivos: descrever as intervenções do enfermeiro em intercorrências clínicas durante a hemodiálise ambulatorial, bem como descrever as principais intercorrências durante as sessões de hemodiálise ambulatorial e se há protocolos específicos de intervenções do enfermeiro em intercorrências com o paciente dialítico.

Tendo em vista que o procedimento hemodialítico tem complicações potenciais e o enfermeiro deva estar apto para intervir em tais complicações, fica evidente a importância deste estudo. Para a realização do mesmo foi utilizado o método de revisão integrativa da literatura com recorte temporal de 2014 a 2018, com exceção do levantamento bibliográfico, que trouxe algumas publicações de anos anteriores.

\section{Desenvolvimento}

\subsection{Metodologia}

Trata-se de uma pesquisa de revisão integrativa da literatura, pois segundo Lakatos e Marconi (2018), se caracteriza por uma coleta dos principais trabalhos científicos já publicados na literatura de forma a fornecer dados atuais e relevantes, relacionados ao tema e tem por propósito realizar uma dada síntese rigorosa de todas as pesquisas encontradas relacionadas a uma questão específica, um tema em estudo, sendo a mais ampla abordagem metodológica referente às revisões, permite incluir desde estudos experimentais, não-experimentais para melhor compreensão do fenômeno analisado pelo pesquisador.

Os critérios de inclusão dos artigos foram: artigos na íntegra, em língua portuguesa, sem custos quaisquer, que contemplaram a luz do tema da presente pesquisa e com o recorte temporal, entre 2014 até 2018, com exceção do levantamento bibliográfico, que trouxe algumas publicações de anos anteriores. Os critérios de exclusão foram: os artigos que não estavam na íntegra, em outros idiomas, com algum tipo de custo financeiro, que não contemplaram a luz do tema da pesquisa e que estiveram fora do recorte temporal.

Para pesquisa e busca dos artigos foram utilizados os descritores: enfermagem, diálise, intercorrências, protocolos específicos e hemodiálise, dessa forma, foram encontrados $464(100 \%)$ artigos, na primeira análise e leitura dos resumos $68(15 \%)$ foram selecionados, destes, após a leitura na íntegra, foram selecionados 28 artigos (40\%). Os bancos de dados utilizados foram: Lilacs, SciELO, Bireme, BVS, BDENF e Pubmed.

A análise dos artigos foi realizada por meio de uma tabela específica, a realização da síntese dos artigos e as suas respectivas interpretações, a fim de realizar o melhor entendimento e compreensão dos aspectos convergentes e integrativos.

As limitações deste estudo foram em relação às dificuldades encontradas e se destaca a pequena quantidade de artigos originais, que tratassem da temática e atendessem aos critérios de inclusão e exclusão, tanto para compor a amostra da pesquisa, quanto para discussão dos achados.

Os resultados foram apresentados por meio das discussões e interpretação com auxílio da literatura empregada.

\subsection{Resultados}

Para pesquisa e busca dos artigos foram utilizados os descritores: enfermagem, diálise, intercorrências, protocolos específicos e hemodiálise, dessa forma, foram encontrados 464 artigos (100\%), na primeira análise e leitura dos resumos 68 artigos (15\%) foram selecionados, destes, após a leitura na íntegra, foram selecionados 28 artigos (40\%).

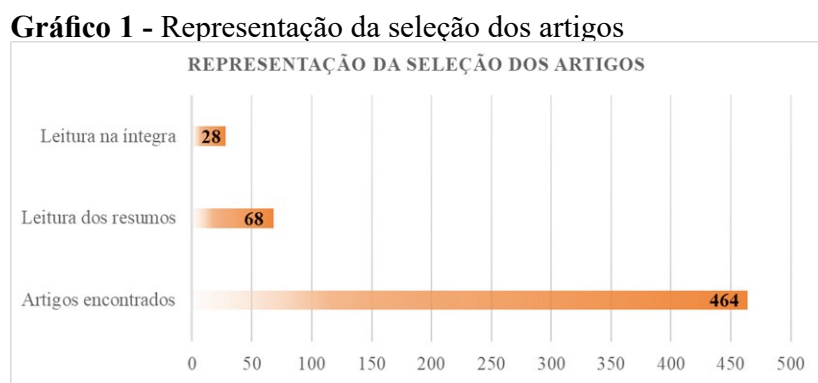

Fonte: Dados da pesquisa.

Para melhor compreensão e integração das informações dos artigos, estes foram organizados e sintetizados na Tabela 1 abaixo. 
Tabela 1. Descrição e síntese dos artigos selecionados

\begin{tabular}{|c|c|c|c|c|c|}
\hline $\mathbf{N}^{0}$ & Artigo & Ano & Fonte & Autores & Síntese dos Artigos \\
\hline 01 & $\begin{array}{l}\text { Enfermagem e Suas Intervenções nas } \\
\text { Principais Complicações Ocorridas } \\
\text { Durante a Sessão de Hemodiálise }\end{array}$ & 016 & $\begin{array}{l}\text { Rev. } \\
\text { Enfermagem e } \\
\text { Saúde Coletiva }\end{array}$ & $\begin{array}{ll}\text { Mayara } & \text { Santos } \\
\text { Silva et al. } & \end{array}$ & $\begin{array}{l}\text { O presente artigo se refere à } \\
\text { importância da intervenção } \\
\text { imediata do enfermeiro diante das } \\
\text { intercorrências em Hemodiálise. }\end{array}$ \\
\hline 02 & $\begin{array}{l}\text { Enfermagem e as complicações frequentes } \\
\text { durante o tratamento hemodialítico }\end{array}$ & 016 & $\mathrm{ReOn} \mathrm{Fr}$ & $\begin{array}{l}\text { Francisca Regina } \\
\text { Costa da Silva et al. }\end{array}$ & $\begin{array}{l}\text { O artigo discorre sobre as } \\
\text { complicações com o doente renal } \\
\text { durante sessões de Hemodiálise. }\end{array}$ \\
\hline 03 & $\begin{array}{l}\text { Diagnósticos e intervenções de } \\
\text { enfermagem do domínio segurança e } \\
\text { proteção para pacientes em hemodiálise }\end{array}$ & 2017 & $\begin{array}{l}\text { Enfermeria } \\
\text { Global }\end{array}$ & \begin{tabular}{|l|} 
Letícia Lima Aguiar \\
e \\
Maria Vilani \\
Cavalcante Guedes \\
\end{tabular} & $\begin{array}{l}\text { Discorre sobre os diagnósticos e } \\
\text { intervenções de enfermagem com } \\
\text { foco na segurança do paciente em } \\
\text { Hemodiálise. }\end{array}$ \\
\hline 04 & $\begin{array}{l}\text { Assistência de enfermagem nas } \\
\text { complicações durante as sessões de } \\
\text { hemodiálise }\end{array}$ & 2018 & $\begin{array}{r}\text { Enferm } \\
\text { Bra }\end{array}$ & 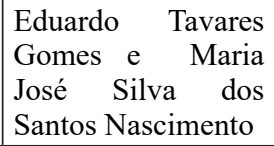 & $\begin{array}{l}\text { Descreve quais são as principais } \\
\text { intercorrências durante a hemodiálise } \\
\text { e as principais intervenções do } \\
\text { enfermeiro. }\end{array}$ \\
\hline 05 & $\begin{array}{l}\text { licações graves evitáveis pela } \\
\text { de enfermagem ao paciente em } \\
\text { liálise }\end{array}$ & 2017 & $\begin{array}{r}\text { Elet. A } \\
\text { Saú }\end{array}$ & $\begin{array}{ll}\text { Thamirys } & \text { de } \\
\text { Carvalho Mota } & \text { et } \\
\text { al. } & \\
\end{array}$ & $\begin{array}{l}\text { O presente artigo aponta as principais } \\
\text { complicações evitáveis durante } \\
\text { sessões de Hemodiálise. }\end{array}$ \\
\hline 06 & $\begin{array}{l}\text { Atuação da enfermagem nas principais } \\
\text { complicações decorrentes do tratamento } \\
\text { hemodialítico }\end{array}$ & 2015 & $\begin{array}{l}\text { Congresso } \\
\text { Brasileiro de } \\
\text { Ciências da } \\
\text { Saúde } \\
\end{array}$ & $\begin{array}{l}\text { Maria Dalva } \\
\text { Eduardo et al. }\end{array}$ & \begin{tabular}{llr} 
Discorre sobre & a & atuação da \\
enfermagem & nas & \multicolumn{1}{c}{ principais } \\
complicações & decorrentes do \\
tratamento hemodialítico.
\end{tabular} \\
\hline 07 & $\begin{array}{l}\text { es em paci } \\
\text { bmetidos à Hem }\end{array}$ & 2017 & $\begin{array}{c}\text { Cog } \\
\text { En }\end{array}$ & $\begin{array}{l}\text { Jéssica Dantas de } \\
\text { Sá Tinôco et al. }\end{array}$ & $\begin{array}{l}\text { O artigo discorre sobre as } \\
\text { complicações durante sessões de } \\
\text { hemodiálise e correlaciona aos fatores } \\
\text { sociodemográficos. }\end{array}$ \\
\hline 08 & $\begin{array}{l}\text { rotocolo de implantação do } \\
\text { nfermagem interfaces com }\end{array}$ & 2016 & $\begin{array}{l}\text { Rev. } 1 \\
\text { UFPE }\end{array}$ & $\begin{array}{l}\text { Felipe Santana e } \\
\text { Silva, et al. }\end{array}$ & $\begin{array}{l}\text { Este artigo evidencia } \\
\text { problemas encontrados } 1 \\
\text { Hemodiálise e propõe } \\
\text { assistencial de enfermag }\end{array}$ \\
\hline 09 & emodiálise e a & 016 & $\begin{array}{r}\text { Enfer } \\
\text { Re }\end{array}$ & Paula Cordeiro & $\begin{array}{l}\text { O presente artigo relaciona as } \\
\text { principais intercorrências durante } \\
\text { a hemodiálise com a assistência } \\
\text { prestada pela enfermagem. }\end{array}$ \\
\hline 10 & $\begin{array}{l}\text { atividades } \\
\text { s em terapia }\end{array}$ & 2017 & $\begin{array}{r}\text { RGI } \\
\text { Gai } \\
\text { Enfe }\end{array}$ & $\begin{array}{l}\text { lia de Fátima } \\
\text { na et al. }\end{array}$ & $\begin{array}{l}\text { O artigo trata da } \\
\text { intervenções de enfe } \\
\text { pacientes em Hemodiál }\end{array}$ \\
\hline 11 & $\begin{array}{l}\text { Temodiálise: Principais complicações em } \\
\text { essões hemodialíticas em uma Unidade } \\
\text { e Nefrologia em Porto Velho-RO }\end{array}$ & 018 & $\begin{array}{l}\text { REAS } \\
\text { Elet. A } \\
\text { Saú }\end{array}$ & $\begin{array}{l}\text { Raida Alves Lima } \\
\text { et al. }\end{array}$ & $\begin{array}{l}\text { Trata das principais complicações } \\
\text { em sessões hemodialíticas em uma } \\
\text { unidade de diálise de Porto Velho - } \\
\text { RO. }\end{array}$ \\
\hline 12 & aça do paciente em tratamento & 2018 & $\mathrm{~m}$ & 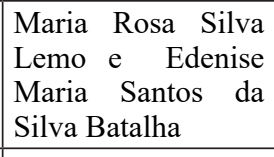 & $\begin{array}{l}\text { Este artigo classifica quais são os } \\
\text { principais eventos que comprometem } \\
\text { a segurança do paciente em tratamento } \\
\text { hemodialítico. }\end{array}$ \\
\hline 13 & $\begin{array}{l}\text { revalência de eventos adversos em uma } \\
\text { nidade de hemodiálise }\end{array}$ & 2016 & $\begin{array}{r}\mathrm{R} \\
\text { Enfern } \\
\mathrm{UB} \\
\end{array}$ & $\begin{array}{|lr|}\text { Maiana regina } \\
\text { Gomes de } & \text { Sousa et } \\
\text { al. }\end{array}$ & $\begin{array}{l}\text { O artigo trata da prevalência de } \\
\text { eventos adversos em uma unidade de } \\
\text { hemodiálise. }\end{array}$ \\
\hline 14 & $\begin{array}{l}\text { pais problemas gerados durante } \\
\text { pia de Hemodiálise associados a } \\
\text { lade da água }\end{array}$ & 2016 & $\begin{array}{l}\text { ev. El } \\
\text { tualiz }\end{array}$ & $\begin{array}{l}\text { Geiza Pereira de } \\
\text { Jesus e } \text { Aline } \\
\text { Almeida }\end{array}$ & $\begin{array}{l}\text { Discorre sobre os principais problemas } \\
\text { em Hemodiálise associados com a } \\
\text { qualidade da água. }\end{array}$ \\
\hline 15 & $\begin{array}{l}\text { Complicações do procedimento } \\
\text { hemodialítico em pacientes com } \\
\text { insuficiência renal aguda: Intervenções } \\
\text { de enfermagem }\end{array}$ & 2016 & $\begin{array}{l}\text { RGE - Rev. } \\
\text { Gaúcha de } \\
\text { Enfermagem }\end{array}$ & $\begin{array}{l}\text { Gabriela Lisangela } \\
\text { Della Flora da Silva } \\
\text { e } \\
\text { Elisabeth Gomes da } \\
\text { Rocha Thomé } \\
\end{array}$ & $\begin{array}{l}\text { Este estudo descreve as complicações } \\
\text { do procedimento hemodialítico em } \\
\text { pacientes com insuficiência renal } \\
\text { aguda. }\end{array}$ \\
\hline 16 & $\begin{array}{l}\text { Intercorrências em hemodiálise e } \\
\text { avaliação da saúde de pacientes renais } \\
\text { crônicos }\end{array}$ & 2015 & AV Enferm. & $\begin{array}{l}\text { Daiana Coitinho et } \\
\text { al. }\end{array}$ & $\begin{array}{l}\mathrm{O} \text { artigo identifica as principais } \\
\text { intercorrências em hemodiálise e } \\
\text { avalia a percepção geral da saúde dos } \\
\text { pacientes renais crônicos. }\end{array}$ \\
\hline 17 & $\begin{array}{l}\text { tividades assistenciais e administrativas } \\
\text { o Enfermeiro nas clínicas de diálise }\end{array}$ & 2016 & $\begin{array}{r}\text { Revi } \\
\text { UNIN }\end{array}$ & $\begin{array}{l}\text { Jéssica Sanches } \\
\text { Silva et al. }\end{array}$ & $\begin{array}{l}\text { Este estudo discorre sobre as atividades } \\
\text { assistenciais e administrativas do } \\
\text { enfermeiro nas clínicas de diálise. }\end{array}$ \\
\hline
\end{tabular}




\begin{tabular}{|c|c|c|c|c|c|}
\hline $\mathbf{N}^{\mathbf{0}}$ & Artigo & Ano & Fonte & Autores & Síntese dos Artigos \\
\hline 18 & $\begin{array}{l}\text { Enfermagem e metas internacionais de } \\
\text { segurança: Avaliação em Hemodiálise }\end{array}$ & 2017 & $\begin{array}{l}\text { Cogitare } \\
\text { Enferm }\end{array}$ & $\begin{array}{l}\text { Letícia Lima Aguiar } \\
\text { et al. }\end{array}$ & $\begin{array}{l}\text { O estudo faz uma avaliação das } \\
\text { metas internacionais de segurança do } \\
\text { paciente em hemodiálise. }\end{array}$ \\
\hline 19 & $\begin{array}{l}\text { O impacto do método de tratamento nas } \\
\text { intercorrências intradialíticas e níveis } \\
\text { séricos de hemoglobina, cálcio e albumina } \\
\text { da pessoa com doença renal crônica }\end{array}$ & 2016 & $\begin{array}{l}\text { Journal of } \\
\text { Aging and } \\
\text { Inovation }\end{array}$ & $\begin{array}{l}\text { Joaquim Carreira } \\
\text { et al. }\end{array}$ & $\begin{array}{l}\text { Este artigo correlaciona o impacto do } \\
\text { tratamento das intercorrências durante } \\
\text { a hemodiálise e os níveis séricos de } \\
\text { hemoglobina, cálcio e albumina. }\end{array}$ \\
\hline 20 & $\begin{array}{l}\text { Características individuais e clínicas de } \\
\text { clientes com doença renal crônica em } \\
\text { terapia renal substitutiva }\end{array}$ & 2014 & $\begin{array}{l}\text { Rev. } \\
\text { Enfermagem } \\
\text { UERJ }\end{array}$ & $\begin{array}{lr}\text { Brunno } & \text { Lessa } \\
\text { Saldanha } & \text { Xavier et } \\
\text { al. }\end{array}$ & $\begin{array}{l}\text { O presente estudo identifica as } \\
\text { características individuais e clínicas } \\
\text { de pacientes com doença renal crônica } \\
\text { que aguardam o transplante. }\end{array}$ \\
\hline 21 & $\begin{array}{l}\text { Panorama da doença renal terminal em } \\
\text { um estado da Amazônia brasileira }\end{array}$ & 2017 & $\begin{array}{l}\text { REME - Rev. } \\
\text { Min. Enferm. }\end{array}$ & $\begin{array}{l}\text { Maria Virgínia } \\
\text { Filgueiras de Assis } \\
\text { Mello et al. }\end{array}$ & $\begin{array}{l}\text { O presente artigo retrata o perfil } \\
\text { sociodemográfico e clínico de } \\
\text { pacientes em hemodiálise. }\end{array}$ \\
\hline 22 & $\begin{array}{l}\text { As ações do enfermeiro ao paciente renal } \\
\text { crônico: reflexão da assistência no foco } \\
\text { da integralidade }\end{array}$ & 2016 & $\begin{array}{l}\text { Rev. de Pesq. } \\
\text { Cuidados é } \\
\text { Fundamental } \\
\text { Online }\end{array}$ & $\begin{array}{l}\text { Luana de Oliveira } \\
\text { Alves et al. }\end{array}$ & $\begin{array}{l}\text { Este estudo objetivou identificar as } \\
\text { ações assistenciais de enfermagem ao } \\
\text { paciente em tratamento hemodialítico. }\end{array}$ \\
\hline 23 & $\begin{array}{l}\text { Complicações em pacientes renais durante } \\
\text { sessões hemodialíticas e intervenções de } \\
\text { enfermagem }\end{array}$ & 2015 & $\begin{array}{l}\text { Rev. de Pesq. } \\
\text { Cuidados é } \\
\text { Fundamental } \\
\text { Online }\end{array}$ & $\begin{array}{lr}\text { R o m a n } & \text { i n y } \\
\text { Hévillyn } & \text { Silva } \\
\text { Costa et al. } & \end{array}$ & $\begin{array}{l}\text { O estudo sintetizou informações } \\
\text { acerca das principais complicações } \\
\text { em hemodiálise e as intervenções de } \\
\text { enfermagem. }\end{array}$ \\
\hline 24 & $\begin{array}{l}\text { Doença renal crônica: relação dos } \\
\text { pacientes com a hemodiálise }\end{array}$ & 2017 & $\begin{array}{l}\text { ABCS - } \\
\text { Arquivo } \\
\text { Brasileiro de } \\
\text { Ciências da } \\
\text { Saúde }\end{array}$ & $\begin{array}{l}\text { Bianca Pozza dos } \\
\text { Santos et al. }\end{array}$ & $\begin{array}{l}\text { Descreve qual a relação dos pacientes } \\
\text { renais crônicos submetidos à } \\
\text { hemodiálise. }\end{array}$ \\
\hline 25 & $\begin{array}{l}\text { A variabilidade na qualidade do } \\
\text { atendimento entre unidades de diálise } \\
\text { do estado de São Paulo e a Portaria }{ }^{\circ} \\
389 / 2014 \text { do Ministério da Saúde do } \\
\text { Brasil }\end{array}$ & 2016 & J. Bras. Nefrol. & $\begin{array}{l}\text { Manuel Carlos } \\
\text { Martins Castro }\end{array}$ & $\begin{array}{l}\text { Correlaciona as variáveis na qualidade } \\
\text { do atendimento entre unidades de } \\
\text { diálise de São Paulo com a Portaria n }{ }^{\circ} \\
\text { 389/2014 do Ministério da Saúde. }\end{array}$ \\
\hline 26 & $\begin{array}{l}\text { Panorama do tratamento hemodialítico } \\
\text { financiado pelo Sistema Único de Saúde } \\
\text { - Uma perspectiva econômica }\end{array}$ & 2015 & J. Bras. Nefrol. & $\begin{array}{l}\text { Fabiana Gatti } \\
\text { de Menezes' et al. }\end{array}$ & $\begin{array}{l}\text { O estudo aponta um panorama do } \\
\text { tratamento hemodialítico financiado } \\
\text { pelo Sistema Único de Saúde. }\end{array}$ \\
\hline 27 & $\begin{array}{l}\text { Competências do enfermeiro especialista } \\
\text { em nefrologia }\end{array}$ & 2015 & $\begin{array}{l}\text { Rev. } \\
\text { Enfermagem } \\
\text { UERJ }\end{array}$ & $\begin{array}{l}\text { Nathalia Billo de } \\
\text { Oliveira et al. }\end{array}$ & $\begin{array}{l}\text { Este artigo descreve as competências } \\
\text { do enfermeiro especialista em } \\
\text { Nefrologia. }\end{array}$ \\
\hline 28 & $\begin{array}{l}\text { Prevalência de Síndrome Metabólica } \\
\text { diagnosticada pelos critérios NCEP-ATP } \\
\text { III e IDF em pacientes em hemodiálise }\end{array}$ & 2015 & J. Bras. Nefrol. & $\begin{array}{l}\text { Marcos Kubrusly et } \\
\text { al. , }\end{array}$ & $\begin{array}{l}\text { O presente artigo analisa a frequência } \\
\text { do diagnóstico de Síndrome } \\
\text { Metabólica em pacientes submetidos } \\
\text { à Hemodiálise. }\end{array}$ \\
\hline
\end{tabular}

Fonte: Dados da pesquisa.

Para melhor familiarização com os artigos selecionados se percebeu a importância de mensurar e brevemente discutir sobre a concentração das classes de trabalho que já se debruçaram sobre as preocupações convergentes do tema estudado. Nesta análise foram identificados que dos profissionais autores de maior concentração foram enfermeiros, graduandos de enfermagem e médicos, respectivamente, contudo, também se analisaram artigos, cujas classes profissionais eram mistas.
Gráfico 2 - Concentração das classes de trabalho dos autores CONCENTRAÇÁO DAS ClaSSES DE TRABALHO dOS AUTORES

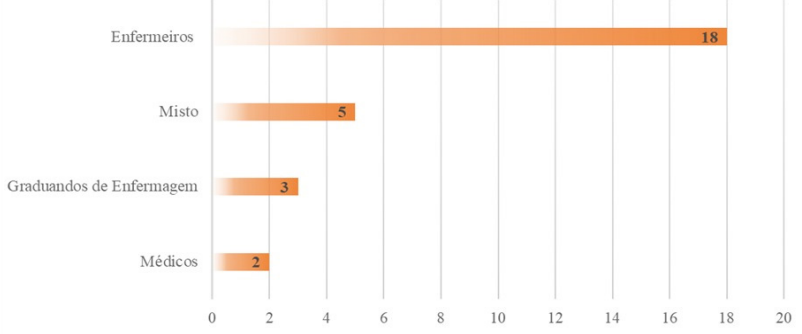

Fonte: Dados da pesquisa.

\subsection{Discussão}

Após a análise final de todos os artigos emergiram três categorias distintas descritas a seguir (Figura 1). 
Figura 1 - Categorização final da análise dos estudos
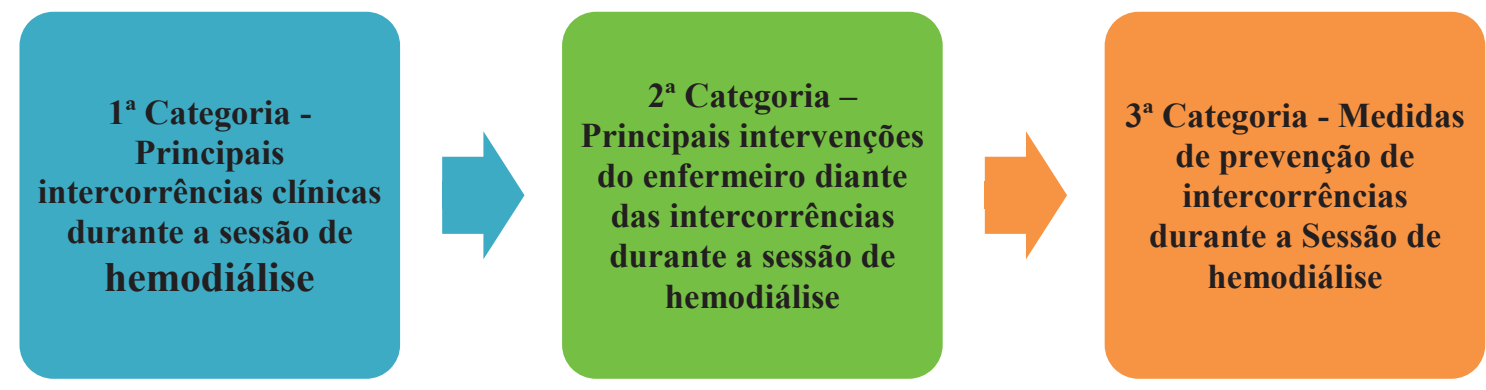

Fonte: Os autores.

\subsection{Principais intercorrências clínicas durante a sessão de hemodiálise}

Por tratar-se de um tratamento invasivo e complexo, os pacientes submetidos à hemodiálise estão mais susceptíveis às complicações durante as sessões.

Nos artigos 1, 2, 4, 7, 9, 11, 14, 15, 16, 22 e 23 os autores concordam que as intercorrências com maior incidência durante a sessão de hemodiálise são hipotensão e hipertensão.

Segundo Silva et al. (2016), tais complicações acontecem em função da instabilidade hemodinâmica dos pacientes e em razão da remoção excessiva de líquidos pela diálise e da reposição inadequada de líquidos.

De acordo com os artigos 1, 2, 4, 6, 7, 9, 11, 14, 15, 16, 19, 22 e 23, além das duas complicações mencionadas acima, durante sessão de hemodiálise ocorre, ainda, outras intercorrências como: hipoglicemia, cãibras musculares, náuseas e vômitos, cefaleia, convulsão, dor torácica, dor lombar, prurido, reações de hipersensibilidade, dispneia, dor abdominal e diarreia

Segundo Nolêto et al. (2017), por vezes, ocorrem intercorrências graves evitáveis como: embolia gasosa; hemólise; reações a resíduos químicos e reação pirogênica que, se percebidas rapidamente podem ser revertidas sem grandes prejuízos ao paciente. A hemólise pode ser causada por "lise" nas células vermelhas do sangue, que resulta em liberação de hemoglobina e declínio no índice de células vermelhas. Ocasionado por problemas na central de tratamento da água, mau funcionamento da máquina, hiper oclusão, contaminação com formaldeído ou outras toxinas desinfetantes, pressão arterial excessivamente negativa, entre outros fatores.

Para Aguiar e Guedes (2017) se estima que as complicações durante a hemodiálise ocorram em $30 \%$ das sessões e, em função de alterações no equilíbrio hidroeletrolítico dos pacientes, fazendo com que a segurança e proteção desses sejam afetadas.

Os artigos 2, 4, 7, 19, 22 e 24, abordam complicações intradialíticas mais graves e até fatais como: hemorragia intracraniana, arritmia cardíaca, embolia gasosa e parada cardiorrespiratória. O que para Silva et al. (2016) acontece em razão da síndrome do desequilíbrio.

Apenas os artigos 2, 13 e 14 mencionam o óbito como uma complicação durante sessões de hemodiálise, sendo essa para Sousa et al. (2016) a mais grave de todas, podendo ter como causa qualquer das intercorrências citadas no presente estudo.

Nos artigos 3, 4 e 9, os autores apresentam complicações de baixa incidência durante as sessões de hemodiálise, sendo essas: hipotermia, hemorragia gastrointestinal e dor nos membros inferiores.

De acordo com os artigos 9, 12, 13 e 14, além das intercorrências intradialíticas relacionadas à instabilidade hemodinâmica dos pacientes, podem ocorrer ainda eventos externos como problemas com acesso venoso (obstrução de cateter, baixo fluxo na fístula etc.) e coagulação do sistema extracorpóreo (decorrente da administração incorreta ou insuficiente de anticoagulante ou solução salina no sistema).

Segundo Gomes e Nascimento (2018), além das complicações inerentes ao tratamento e à instabilidade hemodinâmica do paciente, os mesmos ainda estão expostos aos potenciais riscos de eventos adversos relacionados à terapia. Entre estes eventos estão: cateter obstruído, retirada acidental da agulha da fístula e coagulação do sistema extracorpóreo. Tais eventos estão relacionados, muitas vezes, com os profissionais (falhas, despreparo, falta de atenção, falha na comunicação) e com a organização do serviço (qualidade dos materiais, falta de recursos, sobrecarga de trabalho, recursos humanos e área física inadequada além da ausência de protocolos específicos).

De acordo com Jesus e Almeida (2016), algumas complicações durante sessões de hemodiálise estão relacionadas com a contaminação da água usada no tratamento. As principais ocorrências foram: anemia, por alumínio, cloramina, cobre e zinco; doença óssea, por alumínio e flúor; hemólise, por cobre, nitratos, cloraminas; hipertensão, por cálcio e sódio; hipotensão, por bactéria, endotoxinas e nitratos; acidose metabólica, por baixo $\mathrm{pH}$ e sulfatos; degeneração neurológica, por alumínio; náusea e vômito, por bactéria, cálcio, cobre, endotoxinas, baixo $\mathrm{pH}$, magnésio, nitratos, sulfatos e zinco; morte, por alumínio, flúor, endotoxinas, bactéria e cloramina. Os autores ressaltam, ainda, a importância do cuidado com os centros de tratamento de água para diálise, pois, assim, muitas complicações são evitadas. 


\subsection{Principais intervenções do enfermeiro diante das intercorrências durante a sessão de hemodiálise}

Para Silva e Thomé (2016), intervenção de enfermagem consiste em qualquer tratamento, baseado no julgamento e conhecimento clínico, realizado por um enfermeiro para potencializar os resultados do paciente/cliente. As intervenções de enfermagem incluem cuidados diretos e indiretos, voltados aos indivíduos, famílias e comunidade.

De acordo com Silva, Marini e Silva (2016), o atendimento ao paciente com doença renal crônica necessita de um olhar mais humano e atento da equipe de enfermagem, em especial do enfermeiro, haja vista que os agravos durante a sessão de hemodiálise ocorrem em função da instabilidade dos sinais vitais e as consequências destas complicações, por vezes, estão vinculadas à assistência prestada.

Relacionaram-se nos artigos 1, 2, 3, 6, 8, 22 e 28 que intervenções relativamente simples como: observar os ciclos da máquina de diálise, atenção aos sinais sonoros (indicativos de alterações na temperatura, no fluxo sanguíneo e na presença de bolhas no circuito) e, ainda, oferecer orientações gerais sobre o tratamento, dar apoio e suporte físico e psicológico, esclarecer dúvidas do paciente, se mostraram medidas eficazes para minimizar impactos negativos no momento das intercorrências.

Os artigos 1, 2, 3, 4, 8, 9, 11, 15, 18, 21, 22 e 27 foram categóricos ao afirmar que as intervenções relacionadas a seguir são necessárias em todas as ocorrências intradialíticas, sendo essas: avaliação do estado geral do paciente, monitorização dos sinais vitais, observação contínua ao paciente, comunicar as alterações ao nefrologista de plantão, administrar medicamentos, conforme prescrição médica, orientação quanto à manutenção do peso, registrar em prontuário toda a assistência prestada.

Dos artigos 1, 2, 4, 9, 11, 15, 23 e 25 emergiram intervenções de enfermagem específicas para hipotensão e hipoglicemia, por se tratar de duas complicações de alta incidência durante sessões de hemodiálise.

Segundo Silva et al.(2016) outras intervenções priorizadas pelos enfermeiros durante os episódios das complicações foram: irrigação do sistema com solução salina, posicionamento do paciente em Trendelemburg, zerar as perdas, alteração da ultra filtração prescrita e suspensão da sessão dialítica, principalmente, nos casos de hipotensão arterial.

Segundo Cordeiro et al. (2016), as intervenções de enfermagem realizadas nos pacientes, que apresentaram hipoglicemia, foram a administração de SG 50\% por via endovenosa conforme prescrição médica, alteração da ultra filtração prescrita e, para os casos de reincidência a sessão de diálise deve ser interrompida. A atuação do enfermeiro diante desta complicação, desde a monitorização do paciente, a detecção de anormalidades e a rápida intervenção é essencial para a garantia de um procedimento seguro e eficiente.
Identificaram-se nos artigos 1, 2, 3, 4, 8, 15, 16, 18, 24, 27 e 28 que a avaliação clínica do enfermeiro, bem como a Sistematização da Assistência de Enfermagem (SAE) são instrumentos eficazes para dar suporte ao profissional no momento da prestação da assistência, priorizando o cuidado individualizado e seguro ao paciente.

\subsection{Medidas de prevenção de intercorrências durante a sessão de hemodiálise}

Após a análise das categorias se notou no emergir da terceira categoria a necessidade de um maior aprofundamento acerca das medidas preventivas sobre as intercorrências intradialíticas e, segundo Aguiar e Guedes (2017), a enfermagem vem desenvolvendo ferramentas como o Processo de Enfermagem (PE), com o objetivo de melhorar a qualidade do cuidado e contribuir para a construção de um caminho profissional mais consistente, além do crescimento intenso e aprimorado da profissão.

Para Gomes e Nascimento (2018), o enfermeiro deve ser responsável pela sistematização, além da rotina de registro de dados, como: peso e sinais vitais realizados pelos técnicos de enfermagem, visto que apenas pelo processo de enfermagem poderá o enfermeiro realizar intervenções que compreendam dimensões subjetivas do paciente, muitas vezes negligenciadas. Os autores defendem, ainda, que o uso de checklist para registro da sessão, contendo dados présessão, do início e do encerramento, aumenta a qualidade e a segurança durante o tratamento.

Nesta categoria, os artigos 1, 2, 3, 4, 8, 10, 16, 23, 25, 26, 27 e 28 convergem quanto ao uso do Processo de Enfermagem (PE) e da Sistematização da Assistência de Enfermagem (SAE) de forma completa, como instrumento de apoio à prestação do cuidado com vistas as particularidades de cada paciente, contando ainda com as contribuições do NANDA/ NIC/NOC. Defendem, ainda, a consulta de enfermagem, a capacitação contínua da equipe e a padronização das técnicas e cuidados inerentes ao tratamento dialítico.

Para Santana, Filha, Lando (2016), o Processo de Enfermagem ainda não está consolidado na maioria dos serviços de saúde do país, ou quando é implantado, ocorre de modo incompleto; por diversas razões, tais como: o tempo que os enfermeiros dispõem para prestar o atendimento ao paciente é insuficiente, os materiais disponíveis dificilmente suprem a necessidade, a equipe de enfermagem, atuando em número reduzido, envolvimento em atividades administrativas e, alguns profissionais não se interessam pelo Processo de Enfermagem, ou ainda, os gestores de saúde desconhecem ou não dão a devida importância à Sistematização da Assistência de Enfermagem.

De acordo com Lemos e Batalha (2018), a qualidade da técnica empregada nos serviços, a comunicação e a relação entre profissionais/paciente/família, e a opinião dos usuários são fundamentais para a melhoria da atenção ao paciente. Reiterando esta afirmação, os artigos 1, 2, 6, 8, 15, 16, 
22, 24, 26, 27 e 28 apontam como medidas de prevenção de intercorrências: orientações gerais, suporte e apoio ao paciente/família, ações educativas para o autocuidado e observação contínua ao paciente.

Os artigos 10,12,13,15,16, 21, 22, 27 e 28 ressaltam a importância da implementação de protocolos específicos e das medidas de prevenção e controle de infecção nos centros de diálise. Para Lemos e Batalha (2018), a implementação de protocolos, de indicadores de avaliação e caracterização dos pacientes de risco são ferramentas gerenciais importantes para o enfermeiro no processo de melhoria da qualidade e da segurança na assistência ao paciente. Essa ferramenta permite redirecionar ações de intervenção e sinalizar a necessidade das orientações educacionais aos clientes e para a equipe assistencial.

De acordo com Silva, Dalbello, Costa (2016), as medidas de prevenção e controle de infecção são atividades primordiais dos enfermeiros na hemodiálise, especialmente, aos pacientes com cateter venoso central, em função da maior exposição a um alto índice de infecção se a técnica correta não for aplicada. Dessa forma, é sua função supervisionar ou desenvolver atividades permanentes de educação para os outros membros da equipe com foco na prevenção de infecção.

\section{Conclusão}

Conclui-se com este estudo que, de acordo com o recorte temporal proposto de 2014 a 2018, apesar da quantidade limitada de artigos, que contemplassem a temática, na íntegra, gratuitos e em português, algumas considerações puderam ser feitas como a evidência de que as principais intercorrências clínicas durante as sessões de hemodiálise ambulatorial, de acordo com a pesquisa, são: hipotensão, hipoglicemia, hipertensão, náuseas e vômitos, cãibras, prurido e hipotermia.

Em relação às intervenções do enfermeiro, em geral, foram: monitoramento hidroeletrolítico, verificação de sinais vitais, administração de medicamentos, conforme prescrição médica e orientações ao paciente.

A atuação do enfermeiro envolve, assim, a rápida detecção desses eventos durante o tratamento hemodialítico e, agilidade para intervir com vistas a garantir a efetividade desse procedimento e melhor estado de saúde do cliente. Torna-se fundamental para garantir uma assistência segura com vistas a atender as necessidades individuais do paciente, que o enfermeiro faça uso de instrumentos já conhecidos como o Processo de Enfermagem (PE) e a Sistematização da Assistência de Enfermagem (SAE) e, ainda, faça a implementação de protocolos específicos para a hemodiálise e forneça capacitação contínua da equipe assistencial.

Em referência aos protocolos específicos de hemodiálise, não foram identificados, nesta produção científica, tornando evidente a necessidade de o profissional enfermeiro ousar na inovação e aprimoramento para elaborar e viabilizar este tipo de instrumento nos centros de diálise.

Diante do exposto se considera indispensável que sejam realizados mais estudos acerca desta temática. Além disso, tais estudos devem ser realizados em diversos contextos de atuação do enfermeiro no processo hemodialítico, como também devem abordar as intervenções de enfermagem.

\section{Referências}

AGUIAR, L.L. et al. Enfermagem e metas internacionais de segurança: avaliação em hemodiálise. Cogitare Enferm., v.22, n.3, p.e45609, 2017. doi: http://dx.doi.org/10.5380/ce.v22i3.45609.

AGUIAR, L.L.; GUEDES, M. V. C.. Diagnósticos e intervenções de enfermagem do domínio segurança e proteção para pacientes em hemodiálise. Enferm. Global, v.16, n.3, p.1-37, 2017. doi: https://doi.org/10.6018/eglobal.16.3.248291.

ALVES, L.O.; GUEDES, C.C.P.; COSTA, B.G. As ações do enfermeiro ao paciente renal crônico: reflexão da assistência no foco da integralidade. Rev. Pesq., Cuid. Fund. Online, v.8, n.1, p.3907, 2016. doi: 10.9789/2175-5361.2016.v8i1.3907-3921.

CARREIRA, J.; CARRAPATO, P.; CORREIA, P. O impacto do método de tratamento nas intercorrências intradialíticas e níveis séricos de hemoglobina, cálcio e albumina da pessoa com doença renal crónica. J. Aging Inovation, v.5, n.3, p. 22-33, 2016.

CASTRO, M.C.M. A variabilidade na qualidade do atendimento entre unidades de diálise do estado de São Paulo e a Portaria ${ }^{\circ}$ 389/2014 do Ministério da Saúde do Brasil. Braz. J. Nephrol., v.38, n.1, p.62-69, 2016. doi: 10.5935/0101-2800.20160010.

CORDEIRO, A.P. et al. Complicações durante a hemodiálise e a assistência de enfermagem. Enferm. Rev., v.19, n.2, p.247-254, 2016.

COITINHO, D. et al. Intercorrências em hemodiálise e avaliação da saúde de pacientes renais crônicos. Avances Enferm., v.33, n.3, p.362, 2015. doi: 10.15446/av.enferm.v33n3.38016.

COSTA, R.H.S. et al. Complicações em pacientes renais durante sessões hemodialíticas e intervenções de enfermagem. Rev. Pesq. Cuid. Fund. Online, v.7, n.1, p.2137-2146, 2015. doi: 10.9789/2175-5361.2015.v7i1.2137-2146.

EDUARDO, M.D. et al. Atuação da enfermagem nas principais complicações decorrentes do tratamento hemodialítico. In: CONGRESSO BRASILEIRO DE CIÊNCIAS DA SAÚDE. p. 1-12, 2016.

GOMES, E.T.; NASCIMENTO, M.J.S.S. Assistência de enfermagem nas complicações durante as sessões de hemodiálise. Enferm. Brasil, v.17, n.1, p.10-17, 2018. doi: 10.33233/eb.v17i1.1127.

JESUS, G. P.; ALMEIDA, A. A. Principais problemas gerados durante a terapia de hemodiálise associados à qualidade da água. Rev. Eletrôn. Atualiza Saúde, v. 3, n. 3, p. 41-52, 2016.

KUBRUSLY, M. et al. Prevalência de síndrome metabólica diagnosticada pelos critérios NCEP-ATP III e IDF em pacientes em hemodiálise. Braz. J. Nephrol., v.37, n.1, p.72-78, 2015. doi: 10.5935/0101-2800.20150011.

LAKATOS, E.M.; MARCONI, M.A. Do trabalho cientifico. São Paulo: Atlas, 2001.

LEMOS, M.R.S.; BATALHA, E.M.S.S. Segurança do paciente em tratamento dialítico. Saúde Rev., v.17, n.48, p.3-20, 2018. doi: 10.15600/2238-1244/sr.v17n48p3-20.

LIMA, R.A. et al. Hemodiálise: Principais complicações em sessões hemodialíticas em uma Unidade de Nefrologia em Porto Velho-RO. Rev. Eletr. Acervo Saúde, v.2178, p.2091, 2018.

LUCENA, A.F. et al. Validação de intervenções e atividades 
de enfermagem para pacientes em terapia hemodialítica. Rev. Gaúcha Enferm., v.38, n.3, 2017. doi: 10.1590/19831447.2017.03.66789.

MELLO, M.V.F.A. et al. Panorama da doença renal terminal em um estado da Amazônia brasileira. REME, v.21, 2017. doi: $10.5935 / 1415-2762.20170004$.

MENEZES, F.G. et al. Panorama do tratamento hemodialítico financiado pelo Sistema Único de Saúde - Uma perspectiva econômica. Braz. J. Nephrol., v.37, n.3, p.367-378, 2015. doi: $10.5935 / 0101-2800.20150057$.

NOLÊTO, I.S. C. et al. Complicações graves evitáveis pela equipe de enfermagem ao paciente em hemodiálise. Rev. Eletr. Acervo Saúde, v.2178, p. 2091, 2017.

OLIVEIRA, N.B. et al. Competências do enfermeiro especialista em nefrologia. Rev. Enferm. UERJ, v.23, n.3, p.375-380, 2015. doi: 10.12957/reuerj.2015.9789.

SANTANA, F. et al. Protocolo de implantação do processo de enfermagem interfaces com a legislação. Rev. Enferm. UFPE online, p.1368-1377, 2016. doi: 10.5205/reuol.7057-60979-3SM-1.1003sup201604.

SANTOS, B.P. et al. Doença renal crônica: relação dos pacientes com a hemodiálise. ABCS Health Sci., p. 8-14, 2017. doi: 10.7322/ abcshs.v42i1.943.

SANTOS, P.R. et al. Comparação dos dados de base entre pacientes com doença renal crônica que iniciam hemodiálise que moram perto e longe da unidade de diálise. J. Bras. Nefrol, v. 36, n. 3, p. 375-378, 2014. doi: 10.5935/0101-2800.20140053.

SILVA, F.R.C. et al. Enfermagem e as complicações frequentes durante o tratamento hemodialítico: revisão da literatura. Rev. Ciênc. Saberes-UniFacema, v.2, n.2, p.207-211, 2016.

SILVA, G.L.D.F.; THOMÉ, E.G.R. Complicações do procedimento hemodialítico em pacientes com insuficiência renal aguda: intervenções de enfermagem. Rev Gaúcha Enferm., v.30, n.1, p.33-39, 2016.

SILVA, J.S.; DALBELLO, M.O.; COSTA, M.A.R. Atividades assistenciais e administrativas do enfermeiro nas clínicas de diálise. Rev. Uningá Rev., v. 28, n. 1, 2016.

SILVA, M.S.; MARINI, T.S.O.; SILVA, C.F.B. Enfermagem e suas intervenções nas principais complicações ocorridas durante a sessão de hemodiálise. REVESC, v.1, n.2, p.45-60, 2017.

SOUSA, M.R.G.; SILVA, A.E.B.C.; BEZERRA, A.L. Q. Prevalência de eventos adversos em uma unidade de hemodiálise. Rev. Enferm. UERJ, v.24, n.6, p.18237, 2016. doi: 10.12957/reuerj.2016.18237.

TINÔCO, J.D.S. et al. Complicações em pacientes renais crônicos submetidos à hemodiálise. Cogitare Enferm., v.22, n.4, 2017. doi: 10.5380/ce.v22i4.52907.

XAVIER, B.L.S. et al. Características individuais e clínicas de clientes com doença renal crônica em terapia renal substitutiva. Rev. Enferm. UERJ, v. 22, n. 3, p. 314-320, 2014. 